\title{
AN OCCASIONALIST RESPONSE TO KORMAN AND LOCKE
}

\author{
David Killoren
}

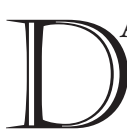
AN KORMAN AND DUSTIN LOCKE argue that nonnaturalists are rationally committed to withhold moral belief. ${ }^{1}$ A main principle in their argument, which they call $\mathrm{EC}^{*}$, can be read in either of two ways, which I call $\mathrm{EC}^{*}$-narrow and $\mathrm{EC}^{*}$-wide. I show that $\mathrm{EC}^{*}$-narrow faces serious problems. Then I show that, if Korman and Locke rely on $\mathrm{EC}^{*}$-wide to critique nonnaturalism, the critique fails. I explain how the availability of a view that I like to call moral occasionalism can be used to respond on the nonnaturalist's behalf to the $\mathrm{EC}^{*}$ wide version of the argument. Moral occasionalism is what is called a "third-factor account" (an explanation of the correlation between moral facts and moral beliefs in terms of some third factor). I show how moral occasionalism is more useful for responding to Korman and Locke than the most widely discussed third-factor account, namely David Enoch's preestablished harmony view.

\section{A DILEMMA FOR KORMAN AND LOCKE'S CRITIQUE OF NONNATURALISM}

To argue that nonnaturalists are rationally committed to withhold moral belief, Korman and Locke rely on a general principle concerning explanation. Before they unveil their principle, they first consider and reject the following "flat-footed" principle:

EC: If $S$ believes that her belief that $p$ neither explains nor is explained

1 Korman and Locke, "Against Minimalist Responses to Moral Debunking Arguments." Korman and Locke's paper won the 2018 Marc Sanders Prize in metaethics. Their argument, more precisely, is that minimalists, who allow that moral facts neither explain nor are explained by moral beliefs, end up being committed to withhold moral belief. There is some question about whether nonnaturalists can reject minimalism (see Shafer-Landau, Moral Realism, ch. 4). But I believe that all nonnaturalists must endorse minimalism, for reasons I explain in Killoren, "Robust Moral Realism," 225-27. So, I will proceed here with the assumption that Korman and Locke's challenge is a challenge for nonnaturalism broadly. 
by the fact that $p$, then $S$ is thereby rationally committed to withholding belief that $p$.

Korman and Locke reject EC because of its bad implications. Concerning a standard example, they write: "You observe the fire in the fireplace and are justified in believing that there is smoke coming out the chimney. Of course, the fact that smoke is coming out of the chimney does not explain (causally or otherwise) the belief that it is. But [contrary to what EC implies] this realization surely does not undermine the belief." ${ }^{2}$ So, Korman and Locke switch away from EC to

EC* If $p$ is about domain $D$, and $S$ believes that her belief that $p$ is neither explained by nor explains some $D$-facts, then $S$ is thereby rationally committed to withholding belief that $p$. (To say that a given fact that $p$ is "about" a given domain $D$ is just to say that the fact that $\mathrm{p}$ belongs to $D$.)

Korman and Locke want to endorse $\mathrm{EC}^{*}$. They argue-not implausibly-that if $\mathrm{EC}^{*}$ were true, that would be bad news for nonnaturalists. Here is why. Any given moral belief is about the moral domain. But nonnaturalism implies that moral beliefs are neither explained by nor explain any moral facts (see note 1 ). So, if $\mathrm{EC}^{*}$ were true, then it would straightforwardly imply that nonnaturalists are rationally committed to withholding all moral beliefs.

But there is an immediate problem for interpreting $\mathrm{EC}^{*}$, which they recognize (but do not try to solve). ${ }^{3}$ The problem stems from Korman and Locke's notion of a domain. Korman and Locke do not explain what a domain is, but presumably it is a type of classificatory structure for facts. The moral domain is one domain; another is the chemical domain (i.e., that domain that contains all and only facts that belong to the science of chemistry); the physical domain is another, and so on.

If we think of domains as classificatory structures for facts, we should expect that there will be overlap between some domains and others, and that some domains will be proper subsets of others. So, any given fact may belong to multiple domains. This highlights an ambiguity in $\mathrm{EC}^{*}$. Consider two versions of $\mathrm{EC}^{*}$. First, a narrow version:

$E C^{*}$-narrow: If [there is some domain $D$ such that $p$ is about that domain, and $S$ believes that her belief that $p$ neither is explained by nor explains any $D$-facts] then $S$ is thereby rationally committed to withholding belief that $p$.

2 Korman and Locke, "Against Minimalist Responses to Moral Debunking Arguments," 324.

3 See Korman and Locke, "Against Minimalist Responses to Moral Debunking Arguments," $324 \mathrm{n} 25$ and discussion on 325 . 
Second, a wide version:

$E C^{*}$-wide: If [for any domain $D$ such that $\mathrm{p}$ is about that domain, $S$ believes that her belief that $p$ neither is explained by nor explains any $D$-facts] then $S$ is thereby rationally committed to withholding belief that $p$.

It appears that Korman and Locke intend $\mathrm{EC}^{*}$ to be equivalent to something close to $\mathrm{EC}^{*}$-narrow. This is suggested by their discussion of a case in which a belief is about multiple domains:

Take the belief that the sun will set in the west. If sunsets and the west are the only domains that this belief is about, then-since this belief is explained by facts about previously observed sunsets in the west $-\mathrm{EC}^{*}$ does not prescribe withholding belief (and rightly so). But if the future also counts as a domain that the belief is about, then $\mathrm{EC}^{*}$ does have the unwanted implication that we should withhold belief about whether the sun will set in the west. So the proponent of $\mathrm{EC}^{*}$ must supply some account of which domains are relevant to assessing whether a belief satisfies $\mathrm{EC}^{*}$, one which excludes the future. ${ }^{4}$

In this paragraph, Korman and Locke gesture at a problem for $\mathrm{EC}^{*}$ that arises from beliefs about the future. Later in this paper, I will develop this problem and will show that this problem is quite serious. But set this aside for now. At the moment, I am interested in this paragraph just because it is useful for interpreting Korman and Locke.

If $\mathrm{EC}^{*}$ were equivalent to $\mathrm{EC}^{*}$-wide, then the case described above would not produce a problem for $\mathrm{EC}^{*}$ (regardless of whether the future counts as a domain that the belief is about). By contrast, if $\mathrm{EC}^{*}$ were equivalent to $\mathrm{EC}^{*}$-narrow, then the case above would produce a problem for $\mathrm{EC}^{*}$ (unless the future is excluded from being a domain that the belief is about). So, given that Korman and Locke in the above paragraph suggest that the case in question produces a problem for $\mathrm{EC}^{*}$ (unless the future is excluded from being a domain that the belief is about), the above paragraph strongly suggests that Korman and Locke think of $\mathrm{EC}^{*}$ as being equivalent to $\mathrm{EC}^{*}$-narrow.

However, I am going to argue (in section 2) that $\mathrm{EC}^{*}$-narrow faces serious problems. This will mean that Korman and Locke should consider alternatives, such as $\mathrm{EC}^{*}$-wide. But (in sections 3 and 4 ) I will argue that even if $\mathrm{EC}^{*}$-wide is true, it is no help to Korman and Locke in their effort to produce a problem for nonnaturalism. That is where moral occasionalism is going to come in.

My thesis is that Korman and Locke face a dilemma. Their critique of non-

4 Korman and Locke, “Against Minimalist Responses to Moral Debunking Arguments," 325. 
naturalism can be founded on either $\mathrm{EC}^{*}$-wide or $\mathrm{EC}^{*}$-narrow. But $\mathrm{EC}^{*}$-narrow is difficult to defend (section 2), and $\mathrm{EC}^{*}$-wide does not provide for a good critique of nonnaturalism (sections 3 and 4 ). Therefore, Korman and Locke's $\mathrm{EC}^{*}$ based critique of nonnaturalism fails. This does not rule out the possibility that some alternative critique of nonnaturalism in the neighborhood of Korman and Locke's might work, though I will discuss some challenges for developing such an alternative critique in the conclusion.

\section{WHY EC ${ }^{*}$-NARROW IS IMPLAUSIBLE}

If we believe that

1. there are infinitely many different facts, and

2. for any given set of facts, there is a domain that contains all and only the facts in that set,

then we should believe that there are infinitely many domains. In this way of thinking, the largest domain will, of course, be the domain that contains all the facts of all sorts. And the smallest domain that contains any given fact that $p$ will be the domain that contains only the fact that $\mathrm{p}$.

If we accept 1 and 2, the problem that Korman and Locke already see for EC (see section 1) will resurface for $\mathrm{EC}^{*}$-narrow. For we should say (given 2 ) that the fact that there is smoke coming out of the chimney $\left(p_{s}\right)$ is contained in a domain $\left(D_{s}\right)$ that contains only $p_{s}$. This - together with the reasonable assumption that the fact that $p_{s}$ neither explains nor is explained by the belief that $p_{s}$ - means that $\mathrm{EC}^{*}$-narrow forbids believing that smoke is coming out of the chimney.

So, if they were to endorse $\mathrm{EC}^{*}$-narrow, Korman and Locke would need to avoid 2. In order to avoid 2, they would need a way of carving and sorting the world of facts into domains such that not just any set of facts counts as a domain. Korman and Locke provide no guidance on that score. There are many possibilities.

According to one idea, domains correspond to disciplines (i.e., forms of inquiry). For example, there are certain sorts of facts that fall within the purview of the discipline of chemistry (e.g., the atomic weight of gold, the structures and properties of carbon compounds) and other facts that fall outside of its purview (e.g., the price of a cup of coffee, the distance between Los Angeles and New York). We might then say that the set of facts in chemistry's purview are chemical facts, and this set constitutes a genuine domain precisely because it constitutes the purview of a genuine discipline. Call this the disciplinary conception of domains. 
An advantage of the disciplinary conception is that it explains why certain sets of facts that intuitively seem like genuine domains, such as the set of all physical facts and the set of all psychological facts, are in fact genuine and separate domains (for those sets of facts are purviews of separate disciplines). Another advantage is that this conception can explain why there are no domains containing only one fact (for there are no disciplines with only one fact in their purview). This conception also has the advantage of excluding certain hodgepodges of facts (e.g., the set of facts that has been explicitly affirmed in sentences written in the French language between 1951 and 1964) from being genuine domains. Because not every set of facts is a genuine domain according to the disciplinary conception, this conception allows us to reject 2 and thus blocks the objection to $\mathrm{EC}^{*}$-narrow discussed above.

But the disciplinary conception does not save $\mathrm{EC}^{*}$-narrow. To see why, consider futurology. Futurology seems to be a genuine discipline; at any rate, it has the trappings of a genuine discipline. (Futurologists hold conferences, publish their findings in books and articles, self-identify as members of a profession, etc.) The facts that fall within futurology's purview are facts about the distant future. So, according to the disciplinary conception, facts about the distant future form a genuine domain — call it the futurological domain. ${ }^{5}$

One of the facts that belongs to the futurological domain is the fact that the sun will burn out five billion years from now. Scientists' belief that the sun will burn out five billion years from now neither explains nor is explained by any futurological facts. So, given the disciplinary conception of domains, $\mathrm{EC}^{*}$-narrow implies that we are rationally committed to withholding belief that the sun will burn out five billion years from now. But we have no such rational commitment. $\mathrm{So}$, given the disciplinary conception, $\mathrm{EC}^{*}$-narrow is false.

To respond to this, the defender of $\mathrm{EC}^{*}$-narrow can reject the disciplinary conception. Indeed, Korman and Locke do not seem to accept the disciplinary conception. For, as we saw earlier, they seem to allow that "sunsets" and "the west"

5 One might say that the futurological domain is not a genuine domain because it is defined by reference to a particular time, namely the time that we happen to occupy. In this way the futurological domain resembles the set of facts about grue things. (A thing is grue if it is observed to be green before $t$ or observed to be blue after $t$; this famous idea is due to Nelson Goodman.) Here it is worth observing that other domains that fall out of the disciplinary conception also involve time in this way. History, for example, is a discipline-and the set of facts in its purview is determined by the point in time that we happen to occupy. (Barack Obama's 2008 election to the presidency is a historical fact today but was not one in 1964.) If one wants to say that a set of facts cannot count as a genuine domain if its membership criteria include reference to a particular time, then one must supply a conception of domains to explain why this restriction holds. It is up to my opponents to supply the needed conception. Thanks to an anonymous referee for pushing me on this point. 
count as genuine domains, but there are no disciplines that focus on those subjects. (There is no Journal of Sunset Studies-alas.)

But if the disciplinary conception is rejected, then a different conception has to be offered in its place. And then a difficult challenge for the critic of nonnaturalism arises. On the one hand, in order to avoid the problems we have already discussed, it is necessary to offer a conception of domains that is restrictive enough to prevent certain sets of facts-e.g., the set of facts about the distant future; the set containing only the fact that smoke is coming out of the chimney-from being genuine domains. On the other hand, if $\mathrm{EC}^{*}$-narrow is going to be used in a Korman and Locke-style critique of nonnaturalism, then it is necessary to offer a conception of domains that is permissive enough to allow the set of moral facts to count as a genuine domain (for the simple reason that the critique relies on the assumption that moral facts belong to the moral domain). It is unclear whether any principled conception of domains can be both restrictive and permissive in the needed ways. Until such a conception of domains is provided, $\mathrm{EC}^{*}$-narrow cannot be used in a persuasive attack on nonnaturalism.

Let us now consider what happens when a critique of nonnaturalism is built on the basis of $\mathrm{EC}^{*}$-wide rather than $\mathrm{EC}^{*}$-narrow.

\section{MORAL OCCASIONALISM TO THE RESCUE}

I will repeat $\mathrm{EC}^{*}$-wide for ease of reference:

$E C^{*}$-wide: If [ for any domain $D$ such that $p$ is about that domain, $S$ believes that her belief that $p$ neither is explained by nor explains any $D$-facts] then $S$ is thereby rationally committed to withholding belief that $p$.

A main advantage of $\mathrm{EC}^{*}$-wide is that, even if the futurological domain is a genuine domain, $\mathrm{EC}^{*}$-wide still does not require us to withhold our belief that the sun will burn out five billion years from now. That is because the fact that the sun will burn out five billion years from now is not only part of the futurological domain. It is also part of various larger domains, such as the physical domain (which contains all and only physical facts), and our belief that the sun will burn out five billion years from now is explained by various physical facts.

If Korman and Locke were to use $\mathrm{EC}^{*}$-wide to show that nonnaturalists are rationally committed to withhold moral belief, they would need it to be the case that nonnaturalism implies the following thesis:

Moral facts are radically disconnected from moral beliefs: For any do- 
main $D$ such that moral facts belong to $D$, moral beliefs are neither explained by nor explain any $D$-facts.

If nonnaturalists believe that moral facts are radically disconnected from beliefs, and if $\mathrm{EC}^{*}$-wide is true, then nonnaturalists are rationally committed to withholding moral beliefs.

To solve this problem, nonnaturalists need to claim that there is some domain that contains moral facts and that also contains facts that explain or are explained by moral beliefs. Then they can deny that moral facts are radically disconnected from moral beliefs. And in that case, nonnaturalists can simply grant $\mathrm{EC}^{*}$-wide and go about their business without further concerning themselves with Korman and Locke's critique.

This is where moral occasionalism comes in. Moral occasionalism allows the nonnaturalist to coherently and plausibly deny that moral facts are radically disconnected from moral beliefs.

Before I can explain why, I need to first explain what moral occasionalism is. According to moral occasionalism, moral grounding facts play a dual explanatory role. First, moral grounding facts (i.e., natural facts that ground moral facts) explain why we hold certain moral beliefs. Second, moral grounding facts make it the case that certain moral facts obtain. Happily, according to the hypothesis of moral occasionalism, the resultant beliefs usually (not always) match the resultant facts. So, our moral beliefs are usually correct—even though moral beliefs neither explain nor are explained by moral facts. ${ }^{6}$

6 There may be a question about whether this picture is compatible with nonnaturalism. Consider:

Natural Grounding: Any fact grounded in a natural fact is itself a natural fact.

If Natural Grounding is true, then moral occasionalism implies that moral facts are natural facts and is thus incompatible with nonnaturalism. So, if moral occasionalism is going to be at all helpful to nonnaturalists, Natural Grounding has to be denied. Here there are many ways that nonnaturalist occasionalists can proceed. First, one could develop a moral occasionalism according to which moral facts are merely normatively grounded in natural facts, not metaphysically grounded in natural facts (cf. Rosen, "Ground by Law"; Bader, "The Grounding Argument against Non-reductive Naturalism"), and then argue that a fact can be merely normatively grounded in a natural fact without being a natural fact. Or one could argue that moral facts are only partially grounded in natural facts, and then argue that a fact can be grounded in a natural fact without being a natural fact as long as it is not fully grounded in natural facts. There are other possibilities. The core point here is that the occasionalist picture requires the thesis that moral facts can be explained by natural facts without being natural facts; different occasionalists can defend and explicate that thesis in different ways. It is beyond the scope of this brief paper to develop this point in detail; for the present purpose it is enough, I hope, to indicate some of the ways in which it could be developed. Thanks to an anonymous referee for pushing me to acknowledge this. 
Here is a handy diagram to illustrate the simple idea:

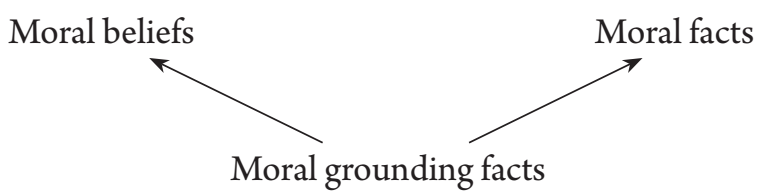

(The arrows in the diagram represent explanatory connections.) To illustrate the moral occasionalist's view, we can use Harman's cat-burning case. A hoodlum sets fire to a cat. An observer sees this. Here is a fact:

$G$ : Setting fire to the cat causes pain to the cat.

In the moral occasionalist's picture, $G$ makes it the case that

$M$ : Setting fire to the cat is morally wrong.

Also, in the moral occasionalist's picture, $G$ makes it the case that

$B$ : The observer forms the belief that setting fire to the cat is morally wrong.

In this picture, there is no direct explanatory connection between $M$ and $B$. Rather, $M$ and $B$ are explanatory siblings: they are both explained by the same grounding fact, namely G. I am calling this picture moral occasionalism because it has the same structure as the picture given by the classical occasionalists. ${ }^{7}$

Moral occasionalism is fully consistent with nonnaturalism. And, as I will now explain, moral occasionalism allows the nonnaturalist to deny that moral facts are radically disconnected from moral beliefs.

There is a set containing all and only moral facts. That is the moral domain. There is another set containing all and only facts that are either moral facts or are moral grounding facts. Call this the moral+ domain.

According to moral occasionalism, a given moral belief that $p$ can be ex-

7 The occasionalists, such as Arnauld and Malebranche, held that there is no causal interaction between our minds and the world. God causes everything that happens in our minds and causes everything that happens in the world. But God is good and so he ensures that what is in our minds mostly matches the way the world is. So, God in classical occasionalism plays the role that moral grounding facts play in moral occasionalism. For an accessible overview of the historical oddity that is classical occasionalism, see Nadler, Occasionalism (especially the introduction). Classical occasionalism, of course, is no longer defended by anyone; but moral occasionalism (of the godless sort described in this paper) avoids many of the vices of classical occasionalism, though I do not have the space to show this here. I will note that when views like moral occasionalism are mentioned, they are often given short shrift. For instance, Matthew Bedke is dismissive of a view in the neighborhood ("Intuitive Non-Naturalism Meets Cosmic Coincidence," 197). 
plained by facts in the moral+ domain (in particular, a given moral belief can be explained by those moral grounding facts that give rise to the fact(s) that the belief in question is about). So, if nonnaturalists endorse moral occasionalism, they can deny that moral facts are radically disconnected from beliefs.

To rebut this occasionalist strategy, my opponents might contend that the moral+ domain is not a genuine domain. But that position is difficult to sustain.

First of all, if we were to accept the disciplinary conception of domains, then the moral+ domain looks to be a genuine domain. For there is a disciplinenamely, the discipline of ethics - that has the moral+ domain as its purview. ${ }^{8}$

Now, as we have seen, Korman and Locke do not have to accept the disciplinary conception and indeed they seem not to accept it. However, rejecting the disciplinary conception is not sufficient to explain why the moral+ domain does not get to count as a genuine domain. Some principled reason why the moral+ domain is not a genuine domain needs to be given.

Here one might claim that hodgepodges of facts are not genuine domains and that because the moral+ domain is defined disjunctively (it contains facts that are either moral facts or moral grounding facts) it is a mere hodgepodge of facts. But the moral+ domain is not a mere hodgepodge of facts. The moral-grounding relation itself is the feature that unifies the moral+ domain: the moral+ domain contains all and only those facts that participate, one way or another, in the moral-grounding relation. Because the moral+ domain is unified in this way, it is not a mere hodgepodge of facts.

Of course, for all that, there may be a conception of domains that explains

8 Ethics as a discipline is not only concerned with moral facts, such as the fact that child neglect is wrong. Ethics is also concerned with the grounds of moral facts. For example, ethicists are interested in facts about the vulnerability of children, the psychological effects of child neglect, and other nonmoral facts in virtue of which child neglect is wrong. (Imagine an ethicist who is asked to explain why child neglect is wrong and declines to answer, saying, "I'm an expert on what's wrong and what isn't, but explaining why this or that is wrong is not my job.") In other words, ethics is not only about moral reality; it is also a study of those parts of the natural world in which moral reality is grounded and of the relationship between moral reality and the natural world. This means that the moral+ domain is squarely within the purview of the discipline of ethics. Here it might be replied that ethics is only concerned with the grounding relationship between morality and the natural world and is not actually concerned with the natural world itself. If this were the case, then moral grounding facts would be excluded from the purview of ethics. But this is not the case. Granted, it seems to be true that the branch of ethics known as normative ethics is unconcerned with any natural facts and is only concerned with principles that connect natural facts with moral facts; but applied ethics is a branch of the discipline as well, and applied ethicists are directly concerned with facts about the natural world (e.g., parts of applied ethics that deal with our obligations to animals are concerned with whether nonhuman animals have the capacity to suffer). 
why the moral+ domain does not get to count as a genuine domain. But until such a conception is provided and tested, the moral occasionalist can reasonably rely on the moral+ domain to respond to a critique of nonnaturalism founded in $\mathrm{EC}^{*}$-wide. ${ }^{9}$

Given this, and given that nonnaturalists can consistently endorse moral occasionalism, $\mathrm{EC}^{*}$-wide does not imply that nonnaturalists are committed to withholding any moral beliefs. Therefore, a Korman and Locke-style critique of nonnaturalism that relies on $\mathrm{EC}^{*}$-wide cannot succeed (unless it is aimed at nonnaturalists who deny moral occasionalism).

\section{MORAL OCCASIONALISM IS AN ATTRACTIVE OPTION FOR NONNATURALISTS}

Let moral optimism be the view that our moral beliefs are correlated with the moral facts, i.e., our moral beliefs are mostly true. Third-factor accounts explain moral optimism in terms of some third factor. David Enoch's pre-established harmony view is the most widely discussed third-factor account. ${ }^{10}$ Moral occasionalism, too, is a third-factor account.

Enoch's pre-established harmony view says that (1) evolution's aim (survival or reproduction or whatever it may be) is good; (2) our moral beliefs are (indirectly) influenced by evolution; and (3) moral optimism is explained by 1 and 2. A main difference between moral occasionalism and Enoch's pre-established harmony view is that the former focuses on proximate causes of moral beliefs whereas the latter focuses on distal causes of moral beliefs. Compare with two ways of explaining the reliability of vision: one could explain this in terms of the evolutionary adaptivity of reliable vision (a distal-cause account) or in terms of the physiological structures and functions of the eye (a proximate-cause account).

These two styles of explanation need not be incompatible, of course. ${ }^{11}$ What

9 A debunker who wants to rely on $\mathrm{EC}^{*}$-wide to critique nonnaturalist occasionalism needs to provide a conception of domains such that (1) the moral+ domain is not a genuine domain, and (2) the provided conception of domains does not inadvertently commit $\mathrm{EC}^{*}$-wide to implausible consequences elsewhere (e.g., it is important that $\mathrm{EC}^{*}$-wide not imply that we have to withhold beliefs that are generally thought to be well-founded, such as beliefs about the distant future). Enoch, Taking Morality Seriously, ch. 7.

This means that moral occasionalists can allow that some Enoch-style evolutionary explanations of moral beliefs are in fact true and do not compete with the explanations that moral occasionalists offer. For the moral occasionalist can allow that moral grounding facts do not fully explain moral beliefs. Other sorts of facts (including facts about the evolutionary forces that have made us into the sorts of beings who are disposed to form correct moral beliefs 
I want to emphasize here is that, for the purpose of responding to a Korman and Locke-style critique based in $\mathrm{EC}^{*}$-wide, Enoch's view has a deficiency that moral occasionalism does not.

Recall the idea that mere hodgepodges of facts do not count as genuine domains. I argued that the moral+ domain is not a mere hodgepodge because it is unified by the moral-grounding relation. Therefore, I argued, even if mere hodgepodges do not count as genuine domains, $\mathrm{EC}^{*}$-wide still does not overturn nonnaturalism when moral occasionalism is in the nonnaturalist's quiver.

Now imagine a version of nonnaturalism that rejects moral occasionalism and accepts Enoch's pre-established harmony view. As we have seen, in order for nonnaturalism to respond to an objection from $\mathrm{EC}^{*}$-wide, it is necessary to identify a domain that contains moral facts and that also contains facts that explain or are explained by moral beliefs. Enoch's view is of no help in identifying such a domain if mere hodgepodges do not count as genuine domains. True, Enoch's view implies that facts about our evolutionary history explain moral beliefs. But a set of facts that combines facts about our evolutionary history with moral facts does seem to be a mere hodgepodge. ${ }^{12}$ So, if mere hodgepodges are not domains, then it seems that Enoch's view offers no resources for constructing a genuine domain that contains both moral facts and facts that explain moral beliefs, which in turn means that Enoch's view is not useful for responding to a critique of nonnaturalism founded on $\mathrm{EC}^{*}$-wide. Moral occasionalism, by contrast, is more effective in responding to such a critique, as we have seen.

in response to moral grounding facts) also enter the explanation of our moral beliefs. Here the analogy with vision is useful. We can rightly claim that facts about our macroscopic surroundings explain our visual experiences while also allowing that other sorts of facts (including facts about the evolutionary forces in virtue of which we have reliable vision) also explain our visual experiences.

Granted, there are some views that can give this set of facts some degree of unity. For example, if you believe that morality is grounded in evolution (such that an action is wrong because that action is maladaptive, or was maladaptive in the environment of our ancestors) then a set containing both evolutionary facts and moral facts would not be a mere hodgepodge. Rather, such a set would be unified by the moral-grounding relation, which I have already granted (in my discussion of the moral+ domain above) is sufficient to avoid the hodgepodge objection. But the idea that morality is grounded in evolution in the needed way is, I believe, highly implausible: it implies, for example, that if we were to make shocking new discoveries about our evolutionary history (e.g., if it were to turn out that child neglect was somehow adaptive for our ancestors) or if we were to learn that we have no evolutionary history at all (e.g., imagine a case where our ancestors emerged whole from a swamp, a la Davidson's Swampman) then we would have to revise our moral beliefs in disturbing ways. And at any rate this evolutionary view of ethics is highly controversial, and it is reasonable to hope that nonnaturalism can be defended without depending on such highly controversial views. 
I have argued that Korman and Locke's critique of nonnaturalism fails, or at least requires substantial elaboration, because moral occasionalism is available to nonnaturalists. I have further argued that moral occasionalism is more useful than Enoch's pre-established harmony view in responding to Korman and Locke. The fact that moral occasionalism is useful to nonnaturalists in this way ought to motivate nonnaturalists to investigate whether moral occasionalism is defensible, and whether it can be incorporated into nonnaturalist views.

But I cannot claim to have shown that nonnaturalists ought to accept occasionalism, because occasionalism faces many challenges that I have not addressed. For one thing, I have not discussed whether moral occasionalism itself might be vulnerable to a debunking argument. At most, I have only shown that if moral occasionalism is true, then Korman and Locke have failed to show that nonnaturalists are rationally committed to withholding moral belief. But it might be that a different Korman and Locke-style debunking argument could show that nonnaturalists are rationally committed to withholding metaethical beliefs, such as the belief that moral occasionalism is true. That challenge is beyond the scope of this paper.

More broadly, if we want to be moral occasionalists, it is not enough to show that moral occasionalism avoids this or that debunking argument. Some positive reason to believe that moral occasionalism is true is also needed. In this paper, I have not tried to offer reasons to believe that moral occasionalism is true; I have only argued that moral occasionalism's availability to nonnaturalism undermines one important critique of nonnaturalism. A positive case for moral occasionalism is a task for another day.

Additionally, I have not shown that Korman and Locke's argument cannot be further refined to deal with the points I have made here. And it is a yet further question whether moral occasionalism can be useful in responding to other critiques of nonnaturalism, including other explanationist critiques that have nothing whatsoever to do with domains. ${ }^{13}$ These issues have to be left for future work on moral occasionalism.

13 Moral occasionalism needs to be tested not only against the variations on Korman and Locke's $\mathrm{EC}^{*}$ discussed in this paper, but also through engagement with alternative constraints such as those developed in Locke, "Darwinian Normative Skepticism"; McCain, Evidentialism and Epistemic Justification; Schechter, "Explanatory Challenges in Metaethics"; Korman, "Debunking Arguments in Metaethics and Metaphysics"; and Lutz, "The Reli- 


\section{REFERENCES}

Bader, Ralf M. "The Grounding Argument against Non-reductive Naturalism." In Oxford Studies in Metaethics, vol. 12, edited by Russ Shafer-Landau, 106-34. Oxford: Oxford University Press, 2017.

Bedke, Matthew. "Intuitive Non-Naturalism Meets Cosmic Coincidence." Pacific Philosophical Quarterly 90, no. 2 (June 2009): 188-209.

Enoch, David. Taking Morality Seriously: A Defense of Robust Realism. Oxford: Oxford University Press, 2011.

Killoren, David. "Robust Moral Realism: An Excellent Religion." International Journal for Philosophy of Religion 79, no. 3 (June 2016): 223-37.

Korman, Daniel. "Debunking Arguments in Metaethics and Metaphysics." In Metaphysics and Cognitive Science, edited by Alvin I. Goldman and Brian P. McLaughlin, 337-63. Oxford: Oxford University Press, 2019.

Korman, Daniel, and Dustin Locke, "Against Minimalist Responses to Moral Debunking Arguments." In Oxford Studies in Metaethics, vol. 15, edited by Russ Shafer-Landau, 309-32. Oxford: Oxford University Press, 2020.

Locke, Dustin. "Darwinian Normative Skepticism." In Challenges to Moral and Religious Belief: Disagreement and Evolution, edited by Michael Bergmann and Patrick Kain, 220-36. Oxford: Oxford University Press, 2014.

Lutz, Matthew. "The Reliability Challenge in Moral Epistemology." In Oxford Studies in Metaethics, vol. 15, edited by Russ Shafer-Landau, 284-308. Oxford: Oxford University Press, 2020.

McCain, Kevin. Evidentialism and Epistemic Justification. Abingdon, UK: Routledge, 2014.

Nadler, Steven. Occasionalism: Causation Among the Cartesians. Oxford: Oxford University Press, 2011.

Rosen, Gideon. "Ground by Law." Philosophical Issues 27, no. 1 (October 2017): 279-301.

Schechter, Joshua. "Explanatory Challenges in Metaethics." In The Routledge Handbook of Metaethics, edited by Tristram McPherson and David Plunkett, 443-58. Abingdon, uk: Routledge, 2018.

Shafer-Landau, Russ. Moral Realism: A Defence. Oxford: Oxford University Press, 2003.

ability Challenge in Moral Epistemology"; among others. I believe that future facts create a problem for some but not all of these types of constraints, but I cannot show this to be the case in this brief response paper. 